\title{
Francisco Javier Alegre (1729-1788): una aproximación a su obra teológica/
}

Francisco Javier Alegre (1729-1788): an approach to his theological work

Inmaculada Alva Rodríguez

Universidad de Navarra, España

Los Institutionum theologicarum libri XVIII de Francisco Javier Alegre son poco conocidos. Esta obra supone un intento de renovar la decadente escolástica, con los nuevos métodos de la teología positiva e histórica. Su originalidad e interés radica en el diálogo que mantiene con los filósofos ilustrados.

La descripción de su contenido y, sobre todo, el estudio de las fuentes que utiliza, muestran un hombre de amplias y variadas lecturas y remiten al ambiente de renovación cultural que impregnó la vida cultural del Virreinato de Nueva España. Refleja también el entorno intelectual de los jesuitas asentados en Italia tras la expulsión y extinción de la Compañía de Jesús.

PALABRAS ClAVE: Francisco Javier Alegre; Jesuitas americanos; Expulsos; Fuentes; Teología.

Little is known about Institutionum theologicarum libri XVIII by Francis Xavier Alegre. This work represents an attempt to renew decadent scholasticism, with the new methods of positive and historical theology. What makes this text original and interesting is its dialogue with the Enlightenment philosophers.

The description of the content and, above all, the study of the sources he relied on, shows a man of wide reading and points to an ambience of cultural renewal that permeated the cultural life of the Viceroyalty of New Spain. It also reflects the intellectual environment of the Jesuits who settled in Italy after the expulsion and suppression of the Society of Jesus.

KEYwords: Francisco Javier Alegre; American Jesuits; Exiles; Sources; Theology. 
La teología del siglo XVIII se desenvolvió en medio de grandes dificultades. La crítica ilustrada a la religión provocó un sentimiento de inferioridad y una actitud defensiva hacia la cultura de las luces. Por otra parte, la decadencia en que estaba sumida la teología escolástica barroca, aislada y envuelta en sus viejos problemas, impedía el desarrollo de un instrumento adecuado para responder a una mentalidad nueva y, con ella, a problemas también nuevos.

En cierta manera, puede decirse que el espíritu de la Ilustración impulsó el deseo de cambio entre los teólogos, sabedores de que se habían removido los cimientos sobre los que estaba asentada la teología, al ser preterido el cultivo de la metafísica y de todo saber que no procediera de la experiencia. En cualquier caso, las intenciones de renovación teológica habían comenzado ya a finales del siglo XVII con la introducción de la teología histórica y positiva ejerciendo una influencia que corre pareja a la de la Ilustración, aunque de forma más lenta.

Por eso resulta interesante estudiar la teología de Francisco Javier Alegre (1729-1788), ${ }^{1}$ pues supone un intento de dar respuesta, desde la escolástica, a algunos temas discutidos en su tiempo, situándose en una actitud de diálogo (y también de confrontación) con los autores ilustrados. Es uno de los últimos intentos de ofrecer un sistema teológico completo que abarcara todas las verdades de fe, porque ya desde el siglo anterior se había iniciado el proceso de las especializaciones teológicas que precisamente culminaría en el XVIII.

Acercarse a la obra de este jesuita implica también aproximarse al ambiente cultural, floreciente y lleno de vitalidad, del Virreinato de Nueva España, abierto a las influencias ilustradas y con grandes impulsos renovadores. En esta tarea ocupa un lugar fundamental la Compañía de Jesús, convirtiéndose muchos de sus miembros en abanderados del nuevo movimiento cultural que también se extendió a la teología.

1 Francisco Javier Alegre (1729-1788), nacido en Veracruz, ingresó en la Compañía de Jesús en 1747. Enseguida destacó por sus prodigiosas capacidades intelectuales y su saber enciclopédico. Dedicó su vida al estudio de la teología, la filosofía, la historia, las lenguas y a la enseñanza en los Colegios de Yucatán y México. Formó parte de una corriente de renovación de la enseñanza en el ambiente cultural de Nueva España. El decreto de expulsión de los jesuitas de los territorios españoles en 1767 y la posterior extinción de la Compañía de Jesús en 1773 le llevó a afincarse en Italia, destino final de muchos exjesuitas. Vivió en Bolonia hasta su muerte en 1788, dejando una abundante obra como La Historia de la Compañía de Jesús de la Provincia de Nueva España, traducciones de obras clásicas o trabajos de física y geometría. 
El objetivo de este trabajo es realizar un acercamiento a la obra teológica de Francisco Javier Alegre, de la que se conocen algunos temas. Alegre se sentía fundamentalmente teólogo y a esta tarea consagró los últimos años de su vida, con el objeto de dejar a la posteridad un instrumento útil para confirmar los dogmas de la fe cristiana y responder a las cuestiones planteadas por los ilustrados.

La fuente principal de esta investigación han sido los Institutionum Theologicarum libri XVIII. Esta obra, amplísima, impresa en los años 1789-1791, no ha sido traducida al castellano de forma completa. Gabriel Méndez Plancarte y Mauricio Beuchot tradujeron y publicaron algunos fragmentos, relativos a las leyes y el origen del poder. Más reciente es la traducción y estudio crítico realizado por el mismo Beuchot, junto con M. ${ }^{\mathrm{a}}$ del Carmen Rovira y Carolina Ponce, de una parte importante de esta obra teológica. ${ }^{2}$

En líneas generales, Institutionum es una obra de carácter enciclopédico - escrita en un latín sencillo y elegante- que pretende abarcar toda la teología, acercándose en estilo a las antiguas Summae y alejándose de la forma de los tratados, que Alegre detestaba. Es un trabajo de gran erudición en el que se exponen importantes temas de la teología, añadiendo las nuevas aportaciones de la teología positiva, con más protagonismo de los Padres de la Iglesia y de la Sagrada Escritura. La obra se ocupa también de las controversias filosóficas modernas y procura alcanzar soluciones. Precisamente, el conocimiento que muestra de los filósofos recientes, los recentiores, le otorga cierta originalidad y supone un intento de diálogo con los problemas planteados por la cultura de su tiempo. En este sentido, se puede hablar de Alegre como un moderno, al apartarse de la línea seguida por la llamada tercera escolástica, encerrada en viejos problemas que ya no interesaban a nadie.

En su tiempo la obra suscitó un gran interés, pues era conocida la erudición y sabiduría de este ignaciano. Suponía además una novedad respecto a la producción teológica del momento. Aunque muchos le dedicaron grandes elogios, en otros provocó también mucha desilusión, pues no quedaban suficientemente realzados los teólogos jesuitas y, sobre todo, porque

2 Méndez Plancarte, 1991, pp. 41-57; Beuchot, 1995, pp. 189-205: traduce el tratado de las leyes (prefacio y prop. I); Beuchot, 1996, pp. 75-89: comenta el tratado del hombre (libro VII, prop. III y IV), el de la guerra justa (libro VII, prop. XXIII) y el de las leyes (libro VIII, prefacio y prop. I); Rovira Gaspar y Ponce Hernández, 2007, pp. 100-425: está traducido el prefacio de Institutionum y los libros VI (prop. XIX y XXI), VII (prop. III, IV y X), VIII (prop. IX), XI (prop. X) y XVIII (prop. VI). 
la línea seguida por él era claramente tomista y no suarista. ${ }^{3}$ Un signo más de su independencia de criterio en la redacción de esta obra.

\section{Intención y objetivos}

Alegre escribió los Institutionum movido por su amor a la Iglesia y el deseo de defender la fe de los ataques sufridos durante el siglo XVIII. Había pasado aquel momento en que creía que la doctrina católica podía ser compatible con las nuevas ideas ilustradas. En su exilio italiano, tomó un contacto más directo con la Ilustración francesa e inglesa, percatándose del marcado carácter anticatólico de autores como Voltaire, Wolff, Hobbes o Rousseau. Aunque se sentía cercano a ellos en determinados temas, como el de la libertad, los derechos de los pueblos, las leyes, la soberanía popular, etc., era también consciente de que la diferencia sobre los puntos de partida y los planteamientos resultaba demasiado grande para lograr una conciliación. Su espíritu ecléctico le movía a aceptar algunas de las conclusiones de estos filósofos, e incluso incorporarlos a su propio razonamiento, pero siempre después de dejar bien claras las diferencias que los separaban.

Otro de sus objetivos era revitalizar la teología escolástica, muy desprestigiada incluso entre los católicos. Existía, desde principios del siglo XVIII, un movimiento de rechazo hacia esta disciplina, que ciertamente había decaído. Alegre reconocía la necesidad de renovarla y purificarla de sus defectos, pero se resistía a desechar un modo de hacer teología que había producido obras tan admirables como la de Aquino. Valoraba el esfuerzo de la escolástica por hacer razonable la fe y la forma como reflejaba la profundidad de los misterios, al dar lugar a diferentes escuelas y opiniones teológicas.

Los destinatarios de su obra aparecen claramente en la dedicatoria y en el prefacio, al dirigirse a los enemigos de la Iglesia, a los obispos y a los jóvenes sacerdotes. Esta variedad de receptores manifiesta el carácter apologético y pedagógico de su libro. ${ }^{4}$ Es interesante subrayar el tono con que Alegre se dirige a sus futuros interlocutores, advirtiendo a los primeros de

3 Decorme, 1941, p. 226, afirma: «Fue, sin embargo, (la obra) una decepción y pena para sus compañeros mexicanos..., tomista hasta los tuétanos, puestos en la penumbra los grandes teólogos de la Compañía, no parece sino que las ruinas del cuerpo habían debilitado las energías de una voluntad que siempre se había sobrepuesto a los recuerdos ingratos».

4 Alegre, 1789-1791, p. III. 
que, a pesar de sus ataques, la Iglesia no será demolida; llamando a los obispos a atender a su responsabilidad de Pastores, como sucesores de los apóstoles y transmisores de la ortodoxia de la fe; ${ }^{5}$ y animando, por último, a la «juventud eclesiástica» a ejercitar su razón en el estudio y profundización de los misterios de la fe. ${ }^{6}$

Al final de su texto, Alegre expone los fines perseguidos con estos libros: confirmar los dogmas de fe; defender la teología escolástica de las injurias y críticas a que se veía sometida; y exponer de un modo sencillo y amable las verdades de fe. ${ }^{7}$ Estos objetivos explican la estructura y extensión de los temas, así como determinadas ausencias o la exhaustividad con que se argumentan otros asuntos.

Los nuevos tiempos exigían una nueva manera de plantear la defensa de la fe católica. Los desgastados razonamientos no podían ya con la nueva mentalidad. Se veía necesario un apoyo más directo en las fuentes, como pedían las nuevas perspectivas de la teología positiva e histórica que desde Petau se venían imponiendo. Esto quería decir que la tarea de confirmar los dogmas exigía clarificar las fuentes y limpiarlas de toda sospecha de falsedad. No se trataba tanto de hacer uso del ingenio y de la razón, non modo via et ratione accurate argumenta premerem, sino de acudir a las Sagradas Escrituras, al magisterio de la Iglesia y a los escritos de los Padres. ${ }^{8}$

\section{La reivindicación de la teología escolástica}

Algunos teólogos católicos, representados por Petau y Thomassin, propugnaban una teología con más erudición histórica, apoyada en los escritos de los Padres. Bien es cierto que no estaban en contra de la teología especulativa en cuanto tal y veían necesario que ésta se apoyara también en una sana filosofía, pero acusaban a la escolástica de haber caído en

5 Ibidem, p. V: «Vestrum igitur hoc opus est. Causa fidei agitur, cuius vos Magistri estis et custodes: Causa gregis agitur, cuius vos estis Pastores: Causa Christi, cuius vos estis Vicarii: Causa Ecclesiae, in qua vos supremno Capiti assidetis Judices».

6 Ibidem, praefatio, p. 6.

7 Ibidem, libro XVIII, prop. XI, n. 14: «Dogmata fidei potissimum confirmare; Theologiae Scholasticae dignitatem et decus a conviciis et reprehensionibus vindicare; faciliusque, et amabilius, ut ita dicam, illius studium Candidatis reddere, qua potui diligentia et contentione praestare studui».

8 Ibidem, libro XVIII, prop. XI, n. 14: «id a me exigebat, ut contra adversarios,..., sed ut ea haurirem a limpidissimis fontibus, a Sacra Scriptura, a Decretis Conciliorum et Summorum Pontificum et a Patrum Scriptis». 
discusiones ociosas que hacían perder de vista el verdadero objeto de esta ciencia. ${ }^{9}$ La escolástica también era atacada por los filósofos ilustrados, a quienes esos argumentos de razón nada decían, porque se referían a temas que no se podían demostrar empíricamente.

Esta clase de teología de finales del siglo XVII y del XVIII era lo que se ha llamado la tercera escolástica o teología barroca, que nada tiene que ver ya con la medieval o la del periodo tridentino. Alejada de la realidad, continuaba enredada en problemas de razón, sutilezas y distinciones, en las que el recurso a los Padres o las Escrituras era muy pobre o meramente decorativo.

Alegre reconocía las limitaciones y defectos de la escolástica de su siglo, pero también apreciaba la rigurosidad de su sistema lógico, que permitía argumentar racionalmente y profundizar en el conocimiento de los dogmas y los misterios de fe. Le parecía que seguía siendo un método válido, aunque con necesidad de ser renovado. En este sentido Beuchot afirma que en el caso de Alegre, y de otros jesuitas coetáneos como Clavijero y Abad, «no se dio, como podría parecer, una abjuración de lo escolástico y una adopción completa de lo moderno. Fue una transición paulatina y bastante equilibrada en comparación con la modernidad europea». ${ }^{10}$

El padre Alegre se lamentaba de los ataques que esta disciplina recibía desde los más variados frentes: Erasmo y Vives se ríen de esta teología, dice Alegre con amargura, y los nuevos filósofos como Mirabeau, Voltaire, Hobbes, etc., la odian y detestan. Pero más grave le parece el ataque de los católicos coetáneos (a los que llama payasos), que se han sumado a las críticas de los enemigos de la Iglesia sin conocer la verdadera razón y origen de la escolástica. ${ }^{11}$

Con esta obra se proponía dar razón de su importancia y dignidad. No se trataba tanto de complicadas elaboraciones intelectuales sino de escribir también con el corazón: «no con elaboradas apologías, que muchas ya han sido escritas por hombres sapientísimos, sino con obras hechas con ardor, de modo que al escribir temas teológicos, aparte los defectos que otros admiten en este tipo de obras»..$^{12}$

9 Mondin, 1996, pp. 489-490.

10 Beuchot, 1996, pp. 113 y ss. En este sentido, ver también Aspe, 2007, pp. 13-14. María del Carmen Rovira elabora una interesante síntesis de este grupo de jesuitas innovadores: Rovira, 2007, pp. 43-59.

11 Alegre, 1789-1791, praefatio, p. 3.

12 Ibidem, libro XVIII, prop. XI, n. 15. 
Se propuso llegar a este fin por medio de tres objetivos. Por una parte, veía necesaria una vuelta a Santo Tomás, pero al verdadero Tomás y no a las interpretaciones que de él se habían hecho. Todo su texto refleja una rendida admiración al Aquinate, «lengua e instrumento de los Padres». Lo consideraba el más grande de los teólogos, tanto «que si alguien después de él ha de ser contado segundo, debe ser tenido próximo a éste, pero próximo con largo intervalo». ${ }^{13}$ Deseaba imitar sus virtudes al hacer teología, su respeto y originalidad al escoger los escritores o la modestia al impugnarlos. ${ }^{14}$ Pretendía utilizarlo, no interpretando, y por tanto oscureciendo su doctrina, sino haciéndolo brillar y acomodando su estilo a los tiempos modernos. ${ }^{15}$

Su segundo objetivo suponía cuidar el estilo de la obra para demostrar que no era propio de la escolástica la oscuridad y complejidad del lenguaje. Por eso se proponía escribir de modo elegante, con la adecuada erudición que el tema necesitase y sabiendo alternar la frase ligera con la argumentación precisa y con la dialéctica según lo pidiera la entidad de la materia. ${ }^{16}$ La escolática no implicaba discutir por el mero placer de hacerlo, sino que era «aquel género de teología que consiste en, presupuesta la doctrina de la fe, explicar y aclarar cada artículo de la fe a través de imágenes adecuadas, las definiciones de las palabras a través de divisiones exactas y las cuestiones más sutiles a través de argumentaciones dialécticas». ${ }^{17}$

El hecho de que las cuestiones no atentaran contra la fe, sino que fueran medios de explicar mejor los misterios, provocaba esa variedad de opiniones y escuelas, que se daba también en las materias profanas. Por eso, se quejaba de que lo que era habitual en otras disciplinas, pareciera innece-

13 Ibidem, praefatio, p. 10: «ut sit quis post ipsum secundus numerandus sit, proximus huic, longo sed proximus intervallo haberi debeat».

14 Ibidem, p. IV. En su alabanza a Santo Tomás, Alegre está explicando las características de una buena teología. Así dice de él que: «neminem Catholicorum rem Theologicam plenius, pressiusque tractasse ac locupletius, neminem aut definisse strictius, aut dividisse subtilius, aut explicuisse dilucidius, aut confirmare nervosius, aut defendisse robustius. Neminem Scripturas aut evolvisse diligentius, aut exposuisse simplicius, aut aduxisse congruentius. Neminem Graecos et Latinos Patres aut trivisse frequentius, aut allegasse opportunius, aut tractasse reverentius. Neminem Philosophos, atque omnis generis profanos authores aut nucleasse accuratis, aut intellexisse rectius, aut Ecclesiasticae doctrinae servire, fecisse felicius. Neminem adversarios fidei sive Paganos, sive Haereticos aut correxisse modestius, aut confutasse efficacius».

15 Ibidem, p. VI: «Sanctum Thomam non e medio sublatum, sed florentem, docentem, regnantem,..., atque ad praesentia tempora acommodato stylo, ac methodo loquentem exhibeo».

16 Ibidem, praefatio, p. 6; libro XVIII, prop. XI, n. 15.

17 Ibidem, praefatio, p. 3. 
sario en teología. ${ }^{18}$ Por supuesto, esta profundización tenía sus límites y él mismo declaraba la importancia de abordar todas esas cuestiones con sobriedad, sin pretender ir más allá de la capacidad y fuerzas de la razón, ni perderse en cuestiones abstractas, confusas o muy complejas, las cuales surgían más de la curiosidad o del mero placer de razonar, que del deseo de explicar los misterios. ${ }^{19}$

Proponía, por tanto, una escolástica renovada, firmemente asentada en Aquino y conectada, en consecuencia, con los Padres. Suponía también la apertura hacia nuevas tendencias filosóficas, en la medida que eran compatibles con la fe, y la huida de viejas cuestiones de escuela. Su intención en esas cuestiones discutidas era poner las diversas opiniones, incluida la suya, para que el lector escogiera la que más le convenciera. ${ }^{20}$

\section{La exposición de la doctrina}

La obra de Alegre tenía también un claro carácter pedagógico. $\mathrm{Su}$ deseo era hacer más fácil y amable el estudio de la teología, ${ }^{21}$ siendo este otro de los aspectos que condicionan su estructura. Una manifestación es el intento de hacer presente la conexión entre las verdades de fe. Por eso, en el prefacio de cada libro suele haber una pequeña recapitulación de los temas estudiados relacionándolos entre sí y preparando lo que se verá a continuación. Presentaba un modelo escalonado en el que las verdades demostradas y afirmadas eran el soporte de las siguientes.

Consideraba que el estudio de la teología sería más fácil en la medida en que ésta fuera depurada de aquellos temas innecesarios que hacían su estudio lento y tedioso, además de utilizar un lenguaje adecuado a la seriedad y dignidad de lo que se estaba tratando. Para expresar mejor esta idea, Alegre comparaba la teología con una matrona a la que se le quitaban los adornos que ya no eran propios de su dignidad y que más le pesaban que adornaban. $^{22}$

18 Ibidem, p. 5: «Ergone Philosophia, Jurisprudentia et Rabbinica Theologia laudabitur Scholastica, christianorum Scholastica Theologia damnabitur, contemnetur, expuetur?».

19 Ibidem, p. 6.

20 Ibidem, libro XVIII, prop. XI, n. 15.

21 Ibidem, libro XVIII, prop. XI, n. 16.

22 Idem: «quemadmodum, si a gravi et pulcherrima Matrona tollas crepundia, quae ea non tam ornant, quam onerant, illamque instruas eo, quae eius decet gravitatem, ornatu». 
Veía la necesidad de introducir los recursos utilizados por las ciencias humanas y entrar en diálogo con las ideas de su tiempo, de modo que el estudio de la ciencia teológica se hiciera más atractivo. Algo de lo que se sentía capaz por haber dedicado muchos años de su vida al estudio de todo tipo de materias. Antes de escribir esta obra había sido conocido como historiador, filólogo, filósofo y también hombre de ciencia. Le parecía que su labor era similar a la que realizaron los hebreos cuando escaparon de Egipto llevándose los útiles, vajillas e instrumentos egipcios para su acomodo personal y culto a Dios. Del mismo modo era legítimo utilizar las riquezas de gentiles y profanos para el honor y la dignidad de Cristo y de la Iglesia. ${ }^{23}$

\section{Estructura de la obra}

La tercera escolástica se identifica por tres caracteres metodológicos que también aparecen en este libro de Alegre: la conservación del método dogmático, en cuanto que significa la afirmación de los grandes principios doctrinales por encima de interpretaciones de escuela; la tendencia a la sistematización de toda la especulación teológica y la organización pedagógica de la teología en forma enciclopédica. ${ }^{24}$

La estructura de la obra revela la concepción de la teología que tenía Alegre. Son dieciocho libros contenidos en siete volúmenes. El primer volumen es una introducción a la obra, dividido en tres prolegómenos que, como se verá, tiene por objeto fundamentar las proposiciones que se enuncian en el resto de los libros. Los demás volúmenes ofrecen una versión histórica de los temas teológicos desde la exposición de la esencia divina hasta la vida eterna, meta del hombre en la tierra.

\section{Los fundamentos de la obra teológica}

La intención de Alegre era colocar bien los fundamentos del edificio teológico que iba a construir. Los cimientos exigían dejar claros tres pun-

23 Idem: «vindicari eodem jure a Christiano homine Gentilium et Profanorum divitias ad Christi et Ecclesiae honorem et decus posse et debere».

24 Congar, 1946, columnas 432-434. 
tos: la autenticidad de los libros sagrados, frente a los protestantes; la autoridad de los romanos pontífices y de los obispos frente a los regalistas y protestantes, y, por último, realizar una crítica de los escritos de los Padres, que permitiera utilizar los libros auténticos. ${ }^{25}$

Quería ofrecer una sólida visión de la fe cristiana, que mostrara la cohesión de las verdades entre sí, y la fortaleza de sus argumentos y pruebas. Esta es la función de los tres prolegómenos que introducen la obra propiamente dicha y que exponen los presupuestos fundamentales, como eran la autoridad del papa y de los concilios. Proporcionaba además a los teólogos un instrumento adecuado en el que apoyar sus afirmaciones y rebatir a los que utilizaban esas mismas fuentes para defender ideas contrarias o desautorizar a los Padres. De ahí, la breve noticia de los papas, concilios y herejías al inicio de la obra, puesto que son argumentos utilizados tanto por los católicos como por los enemigos de la fe, para defenderla unos, para atacarla los otros. ${ }^{26}$

Lo primero que deseaba dejar claro era la autoridad del romano pontífice. De hecho, la obra arrancaba con la declaración solemne del nombramiento de Pedro como vicario de la Iglesia, nombrado por Cristo. La primera piedra quedaba así explicitada aunque más tarde, en su capítulo correspondiente, se procediera a su demostración rigurosa (quod postea multis probabitur, nunc supponimus). ${ }^{27}$ Este propósito explica la ausencia de aspectos negativos al exponer la breve historia de los papas. Se trataba de reflejar aquellas cosas que se referían a la fe. Por eso, al hablar de Clemente XIV sólo dice que suprimió la Compañía de Jesús, pero no hace ningún juicio de valor. Sin embargo, cuando alude a Pío VI, el último que reseña, deja aflorar levemente su agradecimiento porque favoreció la permanencia de los jesuitas en Rusia y se ocupó de que el último general de la Compañía, Lorenzo Ricci, fuera enterrado con los debidos honores. Vivat et bonis faveat, le desea al final de este prolegómeno. ${ }^{28} \mathrm{~A}$ la breve historia de los papas sigue una relación de los concilios celebrados en la Iglesia y que constituyen también una fuente indispensable para conocer las verda-

25 Alegre, 1789-1791, libro XVIII, prop. XI, n. 14.

26 Ibidem, prolegomenon I, n. 1.

27 Ibidem. La declaración del primado de Pedro se expresa con una gran solemnidad: «Jesus christus Dei filius, Simonen Joannis flium, Andreae fratrem, Bethsaidae in Galilea natum, novo nomine insignivit suique in terris Vicarium, et Ecclesiae ab se instituendae caput futurum promisit... Petrum igitur primum Christi in terris Vicarium fuisse et Romanam Ecclesiam instituisse, authoritatemque suam in sui Episcopatus succesores derivasse».

28 Ibidem, p. 118. 
des de fe. Unida a la importancia de los concilios y la autoridad de los papas está la de los obispos. Tres puntos que argumentará detalladamente en el libro XI. ${ }^{29}$

Es interesante llamar la atención sobre el esfuerzo de Alegre para realizar una labor crítica de las obras de los Padres. Este esfuerzo muestra a un teólogo en consonancia con el espíritu de su tiempo, en el que la historia está teniendo un valor cada vez más ascendente, y lo conecta con los intentos, aún muy incipientes, de desarrollo de la teología histórica. En esta labor de revisión y depuración acude a los mejores críticos en el prolegómeno III que dedica a esta tarea. ${ }^{30}$

Los prolegómenos contienen también una breve relación de herejes y herejías y, finalmente, un catálogo de escritores eclesiásticos por siglos. En general, en la larga relación de los escritores eclesiásticos sólo da unos pocos detalles biográficos y enumera sus obras más importantes. Apenas se detiene a hacer una valoración crítica, excepto en el caso de Santo Tomás, al que alaba por la «estabilidad de sus principios, consecución, conexión y uniformidad de sus doctrinas, su candor, modestia e inimitable simplicidad de estilo, la mesura, la propiedad y elección de las palabras, la agudeza y solidez de sus argumentos, la claridad en la respuesta, la brevedad al definir, la sutileza a la hora de distinguir». ${ }^{31}$

Demuestra la amplitud de sus lecturas, de sus intereses y la cantidad de obras bibliográficas y prontuarios que manejaba con un claro deseo de exhaustividad. Incluye también autores de la tradición oriental como Gregorio Palamas o Nicolás Cabasilas y, por supuesto, aparecían teólogos del ámbito americano como Pedro de Ortigosa ${ }^{32}$ o Juan José Eguiara y Eguren. ${ }^{33}$ Aunque en principio no aparecen juicios valorativos, a veces aflo-

29 Ibidem, libro XI y libro XVIII, prop. XI, n. 14.

30 Ibidem: «In III Prolegomeno Patres viritim, singulorumque Scripta ex celebriorum Criticorum judicio recensui, atque probata et vera ab spuriis, ac dubiis separavi».

31 Ibidem, prolegomenon III, p. 354.

32 Pedro de Ortigosa, nacido en Ocaña en 1546. En 1577 empezó a dar clases en el Colegio Máximo de México y en la Universidad. Fue teólogo y consultor del III Concilio Mexicano. Escribió varias obras de teología entre las que destacan De fide, spe, et caritate, De angelis y De sacra theologia. Murió en 1626. Un estudio de la vida y obras de este teólogo puede verse en Saranyana, 1999, pp. 342-351, 412-416.

33 Juan José de Eguiara y Eguren (1969-1763), natural de México. Ocupó la cátedra de Teología en la Real y Pontificia Universidad de México de 1724 a 1747, en que se jubiló de la docencia, aunque continuó en esa Universidad como rector, al ser nombrado en 1749. Fundó con su hermano la «Nueva Imprenta de la Biblioteca Mexicana». Su obra teológica más importante es la Selectae Dissertationes Mexicanae aunque es más conocido por la Bibliotheca Mexicana, un diccionario alfabético de autoridades novohispanas. Saranyana, 2005, pp. 220-229. 
ran algunos en los que se puede detectar cierta amargura. De hecho, podemos sentir su antipatía hacia Bayle o Spinoza, su desencanto por Petau, su indiferencia hacia Álvaro de Cienfuegos, cuya obra tradujo, pero también cierta admiración por Leibniz.

Esta parte de fundamentos continúa en los cuatro primeros libros, centrados en Dios y en su revelación, es decir, dónde se encuentra y en qué estado se halla, y en el décimo, sobre Jesucristo. Primero Dios, cuya existencia puede ser demostrada por la razón, así como sus atributos. Esto es lo que Alegre desarrollará a lo largo de veinticuatro proposiciones. La demostración racional de la existencia de Dios es el presupuesto básico para estudiar lo que conocemos de Él por la razón: que es uno, simple, perfectísimo, inmenso, todopoderoso, feliz, providente, justo, causa de todas las cosas, su conocimiento y su voluntad. El último tema que enlaza con los siguientes libros será la demostración de que la revelación no repugna a la razón, aunque no pueda demostrarse. Afirma de todas formas que, en cierto sentido, la revelación era necesaria.

Los libros segundo al cuarto están dedicados a la Palabra de Dios. Pasa revista, en primer lugar, a cada uno de los libros del Antiguo Testamento y ahí estudia su autenticidad y expone quién es el autor de cada uno cuando se conoce. Determinado el canon de la Biblia, realiza en el libro tercero un examen crítico sobre las distintas versiones de las Sagradas Escrituras: el estado de los códices griegos y judíos, la versión de los setenta, las versiones latinas, orientales y protestantes, señalando los aciertos y errores de unas y otras. También dedica este libro a demostrar la necesidad de la interpretación de la Biblia, porque ésta no es clara por sí misma, y desarrollará los distintos sentidos que se encuentran en los pasajes bíblicos. El cuarto libro versa sobre la Tradición. Con argumentos de razón demuestra su necesidad y autoridad.

El libro décimo, aunque separado de éstos, responde al mismo planteamiento de fundamento de la teología. Dedicado a Jesucristo Redentor, revelador y revelación al mismo tiempo. Por eso en la primera parte se habla de Cristo, plenitud de la revelación, el Mesías anunciado en las Escrituras, y de los evangelios y cartas que componen el Nuevo Testamento donde está contenida la palabra que nos ha transmitido. Por tanto, guarda relación con el libro primero que trata de Dios y con el segundo que estudia la canonicidad del Antiguo Testamento. La segunda parte se refiere ya a lo que Jesucristo nos ha revelado acerca de sí mismo. De este modo, como él mismo dice, «establecida la existencia y autoridad de la divina 
revelación, ahora ha de ser emprendido el estudio de las cosas que hay en estos libros sagrados»..$^{34}$

\section{Los misterios revelados en el Antiguo Testamento}

El hombre es el centro de esta sistematización teológica. Pero como el propósito es estudiar el contenido de lo que Dios ha revelado, se tratan en primer lugar, en el libro quinto, el mundo y los ángeles. Se nota una clara preferencia por la creación espiritual, pues el mundo sólo le ocupa las cinco primeras proposiciones de las veintiséis que componen el libro. De hecho, Alegre consideraba que lo material y corpóreo no era objeto de la teología, ${ }^{35}$ y es posible además que quisiera destacar la existencia de seres espirituales para contrarrestar el materialismo.

Las cuestiones sobre el mundo son pocas y sencillas. Se centran en demostrar la creación del mundo por Dios de la nada, que tuvo un principio, que no es necesario y que es uno. Esta última proposición muestra su gusto por la astronomía y el conocimiento que tenía de los últimos hallazgos científicos en ese campo. Los ángeles tienen un amplio tratamiento. Estudia su naturaleza inmaterial, el modo de conocimiento y su voluntad libre. Se entretiene en exceso en dilucidar los grados y jerarquías entre ellos y por último explica quién es el ángel de la guarda y los demonios.

A partir del libro sexto comienza Alegre su estudio sobre el hombre. Establece una separación entre el hombre en estado natural, libro sexto; elevado al orden sobrenatural, libro séptimo, y el hombre caído, libro noveno. Esta distinción es quizá un lastre de cierta teología postridentina en su intento por resolver algunas de las cuestiones agitadas por la crisis luterana y, particularmente, por las «soluciones» propuestas por Miguel Bayo. Aunque en el libro octavo expone su opinión de que no se pueden separar ambos órdenes en el hombre.

El citado libro sexto explica el origen del hombre, la naturaleza del alma y demuestra la existencia de una voluntad libre. Discute aquí con los filósofos ilustrados y trata de mostrar la falsedad e incoherencia de sus afir-

34 Alegre, 1789-1791, libro V, praefatio.

35 Ibidem, libro V, prop. V, n. 23: «Atque haec satis de Opificio Mundi in genere dicta sunt. Nunc ad singulorum operum, quae propius ad Theologicam considerationem pertinent, discussionem accedamus». También en el prefacio del libro VI explica que sólo se ocupará del alma y sus operaciones y virtudes, porque el cuerpo no compete a los teólogos. 
maciones. Pero la mayor parte del libro se centra en el desarrollo de las virtudes morales e intelectuales. Son los dones con los que Dios ha dotado a la naturaleza humana y que el hombre puede hacer crecer con el ejercicio. La fortaleza, prudencia, justicia y templanza son explicadas junto con sus virtudes derivadas y vicios opuestos. La justicia le lleva a hacer una consideración sobre el origen y naturaleza del poder, donde se pronuncia en contra de la esclavitud. ${ }^{36}$

El hombre elevado al orden sobrenatural es la materia del libro séptimo. En primer lugar, estudia el principio de esa vida sobrenatural, que es la gracia. Tratar este tema supone explicar la acción de la gracia en el hombre y dilucidar lo que éste puede hacer con o sin ella, para salir al paso de las controversias escolásticas y de las posturas de Bayo, de los protestantes y de Jansenio. Aclarados estos asuntos se centra en las virtudes infusas y dones del Espíritu Santo que vienen con la gracia. También dedica algunas proposiciones a los frutos del Espíritu y a las gracias extraordinarias como las locuciones, profecías y milagros. Al hablar de la paz, fruto del Espíritu Santo, deriva de ésta una proposición en la que trata del derecho a la guerra. ${ }^{37}$ Como en el caso del origen del poder, parecen un poco fuera de lugar en una parte de carácter más espiritual.

La otra ayuda que el hombre ha recibido de Dios es la ley ${ }^{38}$ Este libro, el octavo, va precedido de un largo prefacio, en el que demuestra la necesidad de que la ley natural esté fundamentada en la divina y la imposibilidad de considerar ambos derechos de forma autónoma, como las nuevas corrientes del derecho estaban defendiendo. Esta introducción precede y sitúa lo que se va a tratar en el libro. En primer lugar, las definiciones: la ley, la ley eterna y la ley natural. A continuación, el lugar donde el hombre puede encontrar más claramente esa ley: está contenida en las Escrituras y resumida en el Decálogo. Examina algunos mandamientos, como el segundo, para hacer ciertas consideraciones sobre la naturaleza del juramento, o el séptimo y la obligación de restituir. Las últimas proposiciones se refieren a la necesidad y origen de las leyes, las competencias del legislador y la diferencia entre derecho natural y derecho positivo.

El último libro, el noveno, se ocupa del hombre caído. Defiende la posibilidad y realidad del pecado en el hombre, justifica que las distincio-

36 Ibidem, libro VI, prop. XI.

37 Ibidem, libro VII, prop. XXIII.

38 Ibidem, libro VIII, praefatio: «interna Dei gratia et favore adjutum, lege ac divinis praeceptis eruditum». 
nes tradicionales sobre el pecado, mortal y venial, personal y original, son distinciones que responden a la realidad de la cosas y no sutilezas escolásticas. El mayor número de proposiciones está centrado en la naturaleza y consecuencias del pecado original, la remisión de los pecados y la predestinación. La última proposición enlaza con el tema del siguiente libro, si el hombre por sí solo puede ofrecer una satisfacción proporcionada a Dios. La respuesta negativa conduce a la necesidad del Redentor, que será ya objeto de la próxima parte.

\section{Los misterios revelados en el Nuevo Testamento}

El primer libro de esta parte, el décimo, tiene una función doble, como ya hemos visto. Está conectado con los primeros libros dedicados a las fuentes de la verdad cristiana, puesto que en él se analizan los libros del Nuevo Testamento, su canonicidad y veracidad y se demuestra que Cristo es el Mesías prometido a los profetas, que había de venir a sacar al hombre de su estado de pecado. ${ }^{39}$ Una vez expuestos los fundamentos de estos nuevos misterios, trata en este mismo libro los temas propiamente cristológicos, apoyándose en los concilios de la antigüedad. La verdadera divinidad y humanidad de Cristo, la distinción de las dos naturalezas en la única persona del Verbo, la maternidad y virginidad de María y la Encarnación son los temas desarrollados por Alegre de una forma bastante tradicional. Cristo, plenitud de la Revelación, le lleva a considerar en las dos últimas proposiciones que la religión cristiana es la más antigua, la verdadera y la más eminente porque es la única que tiene a Dios por autor.

Después de Jesucristo, lo más lógico es estudiar la Iglesia, ${ }^{40}$ tema de los libros once y doce. En el primero tratará la Iglesia en general y, sobre todo, su cabeza. Los asuntos que aquí se examinan van dirigidos a los protestantes y a los regalistas. Por eso, tiene gran interés en demostrar la visibilidad de la Iglesia, quiénes pertenecen verdaderamente a ella y las notas de la verdadera Iglesia. Pero el tema más importante es el de la autoridad, que ocupa la mayor parte de las proposiciones. Primero demostrar que la Iglesia tiene potestad legislativa, en segundo lugar de qué modo y por quié-

39 Ibidem, libro X, praefatio.

40 Ibidem, libro XI, praefatio: «de Ecclesia, quam acquisivit Sanguine suo, opportune venit instituenda tractatio». 
nes es detentada. En cuatro proposiciones se justifica y explica el Primado del papa y finalmente establece la autoridad y utilidad de los legítimos concilios. Como puede observarse, lo que se refleja es una concepción muy juridicista de lo que es la Iglesia.

El interés del libro doce radica en el estudio que se hace de los miembros de la Iglesia, en particular, clérigos, monjes y laicos. ${ }^{41}$ Claramente el lugar principal de esta exposición lo ocupan los pastores, pero centrado sobre todo en justificar su autoridad sobre los fieles. Distingue también cada uno de los siete órdenes sagrados, testimoniando su antigüedad. En una larga proposición defiende y explica la autoridad que tienen los obispos por derecho divino, donde se sitúa en un justo medio entre el regalismo y el ultramontanismo. ${ }^{42}$ Los religiosos son tratados en seis proposiciones en torno a los consejos evangélicos y a las diversas congregaciones y estados de perfección que existen en la Iglesia. Se habla de los laicos en un escolio de la proposición diecinueve sobre los estados de perfección y, en breves líneas, se explica que el término viene de la palabra laos, que significa pueblo, y remite al libro en el que habla de las virtudes. ${ }^{43}$ No considera que sea necesario decir más sobre los laicos.

Antes de pasar a estudiar los sacramentos de la Nueva Ley y los mandamientos de la Iglesia, que forman un bloque coherente, Alegre reúne en un solo libro, el decimotercero, los misterios contenidos en el Símbolo de la fe, misterios revelados a la Iglesia, que le quedan por explicar y no encajan en la estructura de los otros libros: la Santísima Trinidad y la resurrección de la carne. Es un libro breve en el que expone los temas que le interesan de ambos misterios. En realidad nos ofrece una síntesis de los problemas tratados en la antigüedad y las soluciones de los concilios sobre la unidad y distinción de personas. También se preocupa de expresar que es un misterio que no repugna a la razón y su fundamentación en las Sagradas Escrituras. Las tres proposiciones finales son argumentaciones de razón sobre la resurrección de los muertos.

Los siguientes libros nos hablan del culto instituido por Cristo, el nuevo sacrificio y los sacramentos de la nueva ley. Por eso demuestra, en pri-

41 Ibidem, libro XII, praefatio: «Et primum quidem de Clericis, qui prae reliquis Christi fidelibus, in sortem Domini vocati sunt, tum de Monachis, qui medium veluti locum, inter Clericos et Laicos tenent, ac demun de Laicis, sive Ecclesiam plebe».

42 Ibidem, libro XII, prop. XIII: «Jure divino Episcopi Presbyteris Superioris sunt».

43 Ibidem, libro XII, prop. XIX, scolion III: en realidad hace referencia a un tratado de Belarmino en el que lo único que interesa de los laicos es saber si pueden dedicarse a los negocios o ser jueces. Alegre considera que estos temas ya se han visto al hablar de la justicia en el libro VI. 
mer lugar, que la misa es verdadero sacrificio, instituido por Jesucristo. En este mismo libro está contenido el estudio de los sacramentos en general, junto con los de la iniciación cristiana. La Eucaristía es la que recibe un tratamiento más detallado para defenderla de los ataques protestantes. Los otros cuatro sacramentos se agrupan en el libro decimosexto. El análisis es muy parecido en todos ellos: la institución por parte de Cristo, que los define como sacramento de la Nueva Ley, la materia y la forma del sacramento, ministro y sujeto. Al terminar de estudiar cada uno se colocan al final los cánones de Trento sobre ese sacramento. La Confesión contiene también un detenido estudio sobre la virtud de la penitencia y la eficacia del dolor de atrición en polémica con jansenistas y protestantes.

El penúltimo libro explica los preceptos de la Iglesia, justificando primero su antigüedad y santidad. Da pie para señalar las fiestas religiosas y la eficacia de algunas costumbres, como el ayuno y la limosna. Especial interés tiene la argumentación de los diezmos y primicias para el sostenimiento de los ministros de la Iglesia y como una manifestación de culto a Dios. El libro decimoctavo se refiere a la vida futura, pero trata en realidad más temas que tienen cierta relación con éste. En primer lugar explica los diversos lugares donde van las almas después de la muerte: purgatorio, limbo, infierno y cielo. Una vez descritos, siguen unas proposiciones sobre la intercesión de los santos, la invocación a éstos y el culto a las imágenes y reliquias. Este libro acaba con una explicación sobre las canonizaciones.

\section{Las fuentes del autor}

Nos encontramos ante una obra de enorme erudición por la abundancia y variedad de las fuentes utilizadas. También es cierto que esta abundancia nos hace plantearnos si realmente manejó todos los autores que cita. Es posible que recurriera a prontuarios y que conociera algunas obras indirectamente a través de otros escritores. Pero no se puede dejar de lado la enorme capacidad para la lectura y desmedido afán de saber que caracterizó a Alegre. El conocimiento que muestra de muchos teólogos y filósofos, como Tomás de Aquino, San Agustín, Tournely, Alexandre, Belarmino, etc. es bastante completo. Si a esto unimos las referencias de sus contemporáneos, puede darnos ciertas pistas y admitir la idea de que una parte importante de las obras que citaba constituyeron una fuente directa de su 
teología. ${ }^{44}$ Porque, además, Alegre no se conformó con exponer el pensamiento de los escritores, sino que acometió toda una fase previa de examen y verificación de las fuentes para emplear sólo aquellas que presentaban garantías de autenticidad, como ya se ha visto. Contaba con los trabajos de Roberto Belarmino o de Natal Alexandre para seleccionar las obras patrísticas fiables, aunque en su época los maurinos ya habían iniciado la edición crítica de los Padres. ${ }^{45}$

\section{Sagrada Escritura}

Alegre la usa muy frecuentemente. Es obvio que la Biblia constituye para él un lugar teológico primero y fundamental. No obstante, a veces es más un apoyo a sus argumentos, que una fuente a partir de la cual construye el razonamiento. Utiliza las Escrituras con cierta coherencia. Así las citas del Antiguo Testamento son más abundantes en la primera parte, mientras que conforme se adentra en los libros que pertenecen a los misterios revelados a la Iglesia, aumenta el uso del Nuevo Testamento. También es cierto que en algunos temas en los que dialoga con los antiguos filósofos o los ilustrados - como el alma, el conocimiento de Dios o las leyes- apenas aparecen fuentes bíblicas, porque se acude más a los argumentos de razón.

Las cuestiones que tienen un mayor fundamento escriturístico son la de la gracia, sobre todo en su relación con la libertad, y la demostración de que Jesucristo es el Hijo de Dios. ${ }^{46}$ Pero aparece sobre todo en las centradas en la Iglesia y los sacramentos. Es aquí donde se adopta el esquema de comenzar con las citas bíblicas para exponer el tema y ya después pasar a los argumentos de los Padres, de los autores eclesiásticos o de razón. Puede verse en las proposiciones que demuestran la visibilidad de la Iglesia o su indefectibilidad ${ }^{47}$ la necesidad del sacrificio de la misa o la potestad de la Iglesia para remitir los pecados. ${ }^{48}$

44 Maneiro y Fabri, 1989, pp. 206-207: Fabri cuenta dos famosas anécdotas que muestran la amplitud de sus lecturas. Una de ellas ocurrió al parecer en Italia, donde un hombre cultivado lo llevó en Fano a su rica biblioteca personal para ponerle a prueba, «mas Alegre le mostró que todos aquellos autores los había visto y repasado antes muchas veces en México, dándole prolija razón de cada uno de ellos».

45 Precisamente los benedictinos de San Mauro se dedicaron a establecer la autenticidad de documentos patrísticos de tal modo que «el rigor erudito y la preocupación por la exactitud de las citas y referencias constituyen la característica principal de su escuela». Saranyana, 1996, p. 128.

46 Alegre, 1789-1791, libro VII, prop. VI; libro X, prop. X.

47 Ibidem, libro XI, prop. II y VI. 
Los libros más utilizados son el Génesis, los Salmos, seguidos por Sabiduría y Eclesiastés. Los profetas Isaías, Jeremías y Ezequiel tienen también representación. Del Nuevo Testamento hay una marcada preferencia por los evangelios de San Mateo, San Juan y por las cartas de San Pablo.

\section{Fuentes clásicas}

La formación humanística de Alegre, propia de los jesuitas, le permitió tener un profundo conocimiento de los sabios clásicos griegos y latinos. ${ }^{49}$ Valoraba, por tanto, lo que éstos aportaron al conocimiento del hombre. Además era una forma de demostrar que la razón podía acercarse a muchos temas. Estaba claro que había todo un campo común para cristianos y no cristianos y era importante demostrar que temas como la existencia de Dios, la inmortalidad del alma o la ley natural no eran invenciones cristianas, sino que formaban parte del patrimonio de la humanidad. Más en una época en la que el gusto por lo clásico se imponía con nueva fuerza.

Esto explica el abundante uso que hace de autores como Platón, Aristóteles, Cicerón y Virgilio, sobre todo en los libros que tratan la existencia de Dios y sus atributos, el mundo, el hombre y sus dones naturales. En el libro VIII, acerca de las leyes, se apoya en Platón, Aristóteles y Cicerón para demostrar la existencia de una ley natural. La Física de Aristóteles y Las leyes de Platón son el fundamento de sus argumentaciones para la demostración de la existencia de Dios. También se apoya en Homero, Hesiodo, Virgilio y Pitágoras para explicar los atributos divinos como la infinitud, la omnipotencia o la inmensidad. Las dudas de Cicerón sobre la existencia de los dioses se convierten en una prueba contra los que afirman que el conocimiento de Dios es evidente. ${ }^{50}$

Dialoga con Epicuro, Lucrecio y Horacio, quienes niegan la omnipotencia y providencia divina. ${ }^{51}$ Demuestra Alegre una gran habilidad para hacerlos hablar entre sí, como por ejemplo, a Demócrito y Aristóteles acer-

48 Ibidem, libro XIV, prop. I; libro XVI, prop. I.

49 Navarro, 1983, p. 86; este autor afirma que «el Padre Alegre fue entre todos (los jesuitas mexicanos de su generación) el de mayor preparación, el de más amplia cultura greco-latina y el de más versatilidad».

50 Alegre, 1789-1791, libro I, prop. I, nn. 1, 4.

51 Ibidem, libro I, prop. XIV, n. 12 
ca del destino y la predeterminación del hombre. ${ }^{52}$ Con esta confrontación aprovecha para mostrar que Aristóteles supo ya expresar verdades de orden natural, que luego serían confirmadas por la Revelación. Fundamenta en Platón, Aristóteles, Pitágoras o Cicerón la afirmación de la espiritualidad del alma, aunque se separa de ellos en la creencia de la transmigración o en cómo entiende Platón la unión entre el cuerpo y el alma. Utiliza a Epicuro o Lucrecio para detectar las raíces de los pensadores materialistas de su tiempo, a los que consideró meros repetidores de los antiguos. ${ }^{53}$

Teniendo en cuenta que la formación humanística de los jesuitas se centra en el ideal humano propuesto por los clásicos, es lógico que se acuda a ellos para desarrollar el tema de las virtudes humanas, tanto intelectuales como morales. En este caso los autores utilizados son Tito Livio, Marcial y Macrobio. ${ }^{54}$ Así, el citado libro VIII tiene como fuentes a Platón, Aristóteles, Plutarco, Cicerón y Séneca. Son la base para la explicación de la ley natural y la defensa ante las acusaciones que se hicieron a los escolásticos de haber infectado los preceptos naturales con otros de carácter religioso para tener sometidos a los hombres. ${ }^{55}$

Por último, las representaciones de los poetas clásicos como Virgilio y Homero sobre la vida después de la muerte son también una fuente importante, pues Alegre considera que la creencia universal en una vida eterna reflejada en esos cantos es uno de los argumentos más convincentes sobre la existencia de la vida futura. ${ }^{56}$

\section{Los Padres de la Iglesia}

El concilio de Trento había resaltado, de forma muy particular, y en polémica con Lutero, el valor de la Tradición como fuente privilegiada de la Revelación. ${ }^{57}$ Sin embargo, Alegre utiliza esa Tradición después de tomar sus precauciones: asegurar la procedencia de las obras, examinar concienzudamente las fiables, y, por último, hacer un trabajo de crítica para

52 Ibidem, prop. XX, n. 5.

53 Ibidem, libro VI, prop. II; prop. III, n. 4, 7.

54 Ibidem, prop. VI.

55 Ibidem, libro VII, praefatio: «Late de hoc argumento inter veteres Philosophos Plato per libros duodecim et Marcus Tullius per libros tres. Multa sparsim in libris Ethicorum tradidit Aristoteles, tum Plutarchus ac Seneca».

56 Ibidem, libro XIII, prop. VIII; libro XVIII, prop. IV.

57 Denzinger, 1973, nn. 1501, 1597. 
determinar las materias en las que no era necesario seguirlos, e incluso podían estar sujetos a error. Las precauciones que muestra, sin embargo, manifiestan que no es un mero seguidor de modas, sino que su elección responde a un método de hacer teología. Es más, a veces reprocha a algunos teólogos se muestren más abiertos a aceptar argumentos de los Padres y a rechazar por sistema los de autores escolásticos, cuando quizás vienen a decir lo mismo. ${ }^{58}$

Es muy grande y variado el número de Padres que recoge en sus páginas. Según Fabri, ${ }^{59}$ parece que aprendió a utilizarlos siguiendo las orientaciones del libro del dominico Natal Alexandre, Expositio Litteralis et moralis Sancti Evangelii y Commentarius litteralis et moralis in Epistolas Sancti Pauli Apostoli. El mismo Alegre cita mucho a este autor como fuente de su obra teológica. ${ }^{60}$ Esto hace pensar, junto con la forma que tiene de citarlos, que muchos de ellos no los manejara directamente sino a partir de algún elenco como el de Belarmino, Baronio o Alexandre.

El método utilizado es el dialéctico. Aunque las fuentes patrísticas pueden aparecer para ilustrar una idea, normalmente el autor expone sus argumentos haciéndolos hablar con otros herejes o escritores ilustrados. También es frecuente que aporte argumentos que contradicen la proposición de Alegre o de otros Padres, para luego aclararlos, o si es una cuestión debatida, dejarla abierta. Los Padres son, en primer lugar, una de las fuentes para el estudio de la formación de los dogmas y de las herejías de los primeros siglos de la Iglesia. Con este fin acude a Ireneo, Tertuliano, Epifanio, Agustín y Teodoreto. ${ }^{61}$

San Agustín es el autor que más aparece. En algunas materias se basa en él como la máxima autoridad, como en la de la gracia o el conocimiento en Dios. ${ }^{62}$ Junto con Santo Tomás, fundamenta la mayor parte de los

58 Alegre, 1789-1791, libro V, prop. II, n. 3: El autor se queja de que Petau asienta admirado ante la clara argumentación de Metodio de Olimpia acerca de la creación del mundo de la nada y rechace el razonamiento escolástico como dificultoso, cuando en realidad están argumentando de la misma forma.

59 Maneiro y Fabri, 1989, pp. 213 y ss.: «adquirió tal facilidad para leer aquellos, que podía perfectamente encontrar los lugares que le eran necesarios y consultar los Padres que más le interesaban para cualquier asunto y en cualquiera de sus obras».

60 El dominico Natal Alexandre (1639-1724) era un autor de referencia en esta época. Destaca por sus historias eclesiásticas y de Sagrada Escritura. Ocupó un lugar eminente en la facultad de Teología de París, lo que le llevó a jugar un papel importante en los asuntos eclesiásticos de su tiempo. Se le atribuyeron tendencias jansenistas y galicanas, acusaciones de las que siempre se defendió con firmeza. Véase Mandonnet, 1909, col. 769-772.

61 Alegre, 1789-1791, prolegomenon II, p. 257.

62 Ibidem, libro I, prop. VIII, n.4; libro VII, prop. V, n. 12. 
temas. Su labor de crítica previa tiene en cuenta que es el autor al que más libros falsos se le han atribuido. Por eso, procura atenerse a los que han sido seleccionados como auténticos por Belarmino y Alexandre. ${ }^{63}$ Trata también de aclarar aquellas afirmaciones que no han sido bien interpretadas, como las relativas al estado natural y sobrenatural del hombre y la acción de la gracia. La guía segura es siempre Tomás de Aquino, porque, según él, «la Summa de D. Tomás no es otra cosa que Agustín sintetizado». Las cuestiones más oscuras, afirma, hay que leerlas desde el Doctor Angélico, como el Antiguo Testamento hay que leerlo desde el Nuevo. ${ }^{64}$ Son muchas las obras que Alegre maneja de este autor, entra las que destaca De Civitate Dei, De libero arbitrio, De genesi ad litteram, Epístolae y Sermones. ${ }^{65}$

Otros Padres utilizados son Juan Crisóstomo, ${ }^{66}$ Jerónimo, Orígenes y Ambrosio de Milán, posiblemente no sólo por la evidente autoridad de estos escritores, sino también por la variedad de temas que trataron. También constituyen un gran apoyo para las afirmaciones teológicas Gregorio y León Magno, además de Basilio y Gregorio Nacianceno. Algunos van apareciendo en función de los temas específicos que trataron. Así, Cipriano es importante en las argumentaciones sobre el primado del papa, quiénes pertenecen a la Iglesia o temas de sacramentos; Hilario de Poitiers aparece como gran exégeta y aportando su sentido de la Iglesia como misterio. Para estos temas acude también a Ireneo de Lyon o Juan Damasceno. De modo más esporádico Alegre recurre a otros como Fulgencio de Ruspe, Atanasio, Gregorio de Nisa, Justino, Tertuliano, Dídimo el Ciego, Gelasio, Minucio Félix, Máximo el Confesor, Eutimio, Teofilacto, etc.

63 Ibidem, prolegomenon III, p. 196: «Nullus est Patrum, qui plures de divinis rebus libros scripserit, nullus, cui tot fuerint libri falso adscripti, quam Agustinus, quum propter argumentorum diversitatem, tum propter ingenii splendorem et nominis celebritatem. Nimis propterea longum esset, ac lectori injucundum de singulis discurrere, praecipue quum Bellarminus, Doujatius, Natalis, per tomos singulos legitima Augustini opera ab adscititiis discreverint.

64 Ibidem, libro VII, prop. V, n. 13: «Quidquid verae Theologiae in Scholastica D. Thomae Summa continetur (...) usque ad ipsorum articulorum fundamenta, ex Agustino ita mutuatum est,ut quemadmodum Novum Testamentum nihil est aliud, quam Vetus revelatum...ita S. Thomae Summa, ubi Theologiam pro magna parte tradit, nihil sit aliud, quam Agustinus contractus, certaque proportione naturalibus principiis alligatus».

65 Otras obras de San Agustín que cita y utiliza son: Enchiridion ad Laurentium seu liber de fide, spe et caritate; De anima et eius origine; De perfectione iustitiae hominis. También alude con frecuencia a Adversus Manicheorum, pero no especifica a cuál de los libros contra los maniqueos se refiere.

66 Es interesante leer la crítica histórica que refleja sobre los textos del Crisóstomo y las discusiones que hubo en su época sobre la autenticidad de algunas de sus obras, como los Comentarios al Evangelio de San Mateo. Alegre, 1789-1791, prolegomenon III, p. 289. 
Por último, hay que destacar la inclusión de algunos Padres hispanos como Orosio, Prudencio, San Paciano de Barcelona y San Isidoro. Es posible que Alegre tuviera cierto conocimiento de ellos por el hecho de proceder de la misma cultura.

\section{Escritores eclesiásticos}

\section{Autores medievales}

El uso de Santo Tomás en este texto es tan amplio que podemos hablar de una obra tomista. Alegre lo advertía ya desde las primeras líneas, en la propia dedicatoria, donde manifestaba una rendida admiración al Aquinate por considerarlo piedra importante del pensamiento teológico. Expone detenidamente su pensamiento, incluso lo copia. Explica las partes oscuras, lo defiende frente a los ataques de otros teólogos católicos y utiliza sus argumentos contra protestantes y filósofos ilustrados, demostrando con esto su firme creencia en la perennidad de la teología aquiniana, por su capacidad de responder a los problemas planteados varios siglos después.En las controversias de escuela siempre prefiere su explicación, porque le parece más sencilla y adecuada frente a las especulaciones de Luis Molina o Francisco Suárez. ${ }^{67}$ Las obras más utilizadas son la Summa Theologiae, la Summa contra gentiles y De veritate. Pero también se encuentran referencias de De malo y De potentia.

El resto de autores medievales utilizados es en general escaso. Aparecen, sobre todo, en los libros I, V, VI y XIII. Excepto en algunos casos, debió utilizar algún elenco que le permitiera sacar los ejemplos adecuados. Los que tienen un tratamiento más extenso son Boecio y San Anselmo. Es posible que leyera De consolatione philosophiae, por el conocimiento amplio que refleja de él, en lo referente a los atributos divinos, la existencia del mal y el misterio de la Trinidad. ${ }^{68}$ Alegre cita también obras de Boecio que no se encuentran en las relaciones de escritos de este filósofo, como De libero arbitrio y Proslogion. Es posible que fueran atribuidas a Boecio en el siglo XVIII.

67 Ibidem, libro I, prop. X., nn. 14-15. Después de haber mostrado las explicaciones de Molina y Suárez sobre el conocimiento de Dios, en el tema de la ciencia media o de la distinción en Dios de la ciencia de las condiciones o la simple inteligencia, dice preferir a Tomás de Aquino: «Si ergo cum D.Thoma loqui volumus, oportet horum mere conditionarum scientiam ad simplicem intelligentiam reducere».

68 Ibidem, props. II, X, XV, XVI y XX; libro XIII, prop. V. 
Anselmo de Canterbury es un autor muy querido para Alegre por su esfuerzo en demostrar racionalmente la existencia de Dios. Es utilizado sobre todo para explicar el conocimiento de Dios y, en especial, cómo es compatible su conocimiento de las cosas futuras con la libertad. También lo encontramos en el libro sobre el pecado, uniendo sus argumentos a los de Santo Tomás. Los libros citados son Concordia praescientia Dei cum libertate, el Proslogion y De libero arbitrio. ${ }^{69}$

También parece conocer a Pedro Lombardo, por Melchor Cano, ya que siempre aparecen unidos en las argumentaciones. Lo mismo ocurre con otros autores, como San Bernardo, del que se limita a repetir frases célebres que ilustran el razonamiento. ${ }^{70}$ Con esta misma intención, más ilustrativa que argumentativa, hace uso de Buenaventura, cuyos libros no aparecen citados de un modo muy identificable. El hecho de que una sus afirmaciones a las de Petau hace pensar que tal vez tomara las citas de este último. ${ }^{71}$ Hugo de San Víctor, Juan Duns Escoto, Beda, Ricardo de San Víctor, son otros teólogos que aparecen en la obra de Alegre, aunque su presencia es escasa.

Es interesante, aunque no son escritores eclesiásticos, el conocimiento que muestra de Avicena y Averroes, quienes aparecen en las proposiciones dedicadas a explicar la naturaleza y propiedades del alma. Como no cita obras, lo más probable es que los conozca a través de la de Santo Tomás, pues estos filósofos siempre se vinculan a los argumentos del Aquinate. ${ }^{72}$

\section{Autores de los siglos XVI al XVIII}

La cantidad de fuentes utilizadas es mayor respecto a los anteriores, no sólo en cuanto el número de autores, sino también porque su uso es mucho más amplio. En el caso de algunos escritores como Cayetano,

69 Ibidem, props. VIII y X; libro VI, prop. IV, n. 21; libro IX, prop. VIII, n. 3.

70 Ibidem, libro VI, prop. IV, n. 9: Alegre está tratando si el libre arbitrio permanece después del pecado original y se apoya para argumentar en una cita del Tractatus de gratia et libero arbitrio de Bernardo de Claraval: «Manet ergo etiam post peccatum liberum arbtrium et si miserum, tamen integrum. Et quod se per se homo non sufficit a peccato excutere, non liberi arbitrii signat destructionem, sed duarum reliquarum libertatum (a peccato nimirum et miseria) privationem».

71 Ibidem, prop. III, n. 14: hablando de la inmortalidad del alma, si es una propiedad natural o sobrenatural, cita una imagen de Buenaventura en la que compara de esta forma: igual que el árbol de la vida es causa de la inmortalidad, así el sacramento es causa de la gracia; prop. IV, n. 19: se une a la afirmación de Tomás de Aquino sobre la voluntad libre del hombre.

72 Ibidem, libro V, prop. I; libro VI, prop. II, nn. 12-14. 
Belarmino o Suárez, ya no se reduce a frases ilustrativas sino que se expone detalladamente su argumento o se les hace dialogar con otros teólogos. Aunque su uso nunca es tan extenso como el de Agustín o Tomás de Aquino, las fuentes principales de los Institutionum se puede decir que forman parte del cañamazo que sustenta la obra de Alegre.

Hay que distinguir a los autores utilizados por sus tratados dogmáticos, y que son fuente para los desarrollos teológicos, de los historiadores de la Iglesia o de la teología, que se convierten en un instrumento indispensable para conocer las obras y el pensamiento de muchos autores cuyos libros no podía Alegre tener delante. Del grupo de historiadores destacan sobre todo Cesare Baronio, Natal Alexandre y Melchor Cano. El primero, Baronio (1538-1607), historiador de la Iglesia y autor de Anales eclesiasti$c i$, permitió a Alegre elaborar la introducción dedicada a las herejías. ${ }^{73}$

Mucho más utilizado fue el dominico francés Natal Alexandre (16391724), ya citado, ${ }^{74}$ autor de varias obras de historia de la Iglesia y al que Alegre considera una autoridad a la hora de discernir la autenticidad de las fuentes patrísticas o de la Sagrada Escritura. Sus textos son de gran ayuda para elaborar los prolegómenos y están en la base de los demás libros de los Institutionum, sobre todo los que se refieren a la Sagrada Escritura o la Tradición. Su opinión suele ser tenida en cuenta en los libros sobre el mundo, la Iglesia o los sacramentos. Casi nunca lo contradice, excepto en sus interpretaciones de Tomás de Aquino, e incluso le atribuye un galicanismo moderado que respeta. ${ }^{75}$

Melchor Cano y su De loci theologici tiene también una presencia frecuente, aportando datos para los temas históricos. Es un libro de referencia al que Alegre generalmente remite, en especial los apartados que tratan de Dios y sus atributos, la Iglesia o los sacramentos. Acerca de las fuentes que utiliza para escribir sobre la autenticidad de las Sagradas Escrituras, afirma que de este tema trataron con mucha erudición Natal Alexandre, Melchor Cano y Belarmino. ${ }^{76}$ Otros autores citados como suministradores de datos de historia de la Iglesia son Luis Gotti, ${ }^{77}$ una de cuyas obras, De vera

73 Ibidem, prolegomenon II, p. 257. Estudios sobre la vida y obra del cardenal Baronio se encuentran en Ingold, 1910, col. 426. Pero sobre todo en Jedin, 1982.

74 Alegre, 1789-1791, prolegomenon II, p. 257.

75 Ibidem, prolegomenon II, p. 257; prolegomenon III; libro II, praefatio.

76 Ibidem, libro I, prop. XXIII, libro II, praefatio; libro III, prop. XII; libro XVI, prop. III.

77 Coulon, 1915, cols. 1503-1507: Luis Gotti (1664-1742), dominico, fue muchos años profesor de filosofía en Salamanca y en Bolonia hasta que obtuvo la cátedra de teología en esta última ciudad. Destaca por sus obras apologéticas y de controversia, en especial contra el calvinismo. 
Christi Ecclesiae, utilizó Alegre. Junto a ésta empleó la de Bernard Lamy, el Apparatus biblicus. ${ }^{78}$

Roberto Belarmino, Denys Petau y Honorato Tournely ${ }^{79}$ pertenecen a este primer grupo que hemos mencionado. Tienen una presencia mayor en la obra de Alegre, puesto que lo acompañan durante gran parte de sus argumentaciones y sus nombres aparecen en los prefacios de cada libro, que es donde suele citar a sus fuentes. Su afinidad con Belarmino es casi absoluta, excepto en algunas interpretaciones de Santo Tomás de las que disiente. ${ }^{80}$ Utiliza sus dotes de controversista para oponerlo a los pensadores ilustrados, a los protestantes o a los filósofos antiguos. De hecho la única obra suya que utiliza es Controversiae. Su presencia se hace más patente en los tratados sobre la Iglesia, la religión o los sacramentos. También, junto con Natal Alexandre, en los libros II, III, IV sobre la Sagrada Escritura y la Tradición. Por lo general, su pensamiento está muy desarrollado, casi se diría que lo copia. El frecuente recurso a Petau y Tournely evidencia que fueron también fuentes de su teología, aunque a ambos les reprocha su desprecio por la escolástica. ${ }^{81}$ Petau aparece de modo tan frecuente como Belarmino, aunque sus razonamientos no están expuestos con la misma amplitud. Utiliza sobre todo su Theologica dogmata. Alegre acude a él para casi todos los temas, excepto en el libro de las Leyes, y es posible que muchos argumentos de los Padres los extrajera de esta obra de Petau que hemos citado.

Recurre a Tournely para determinados temas dogmáticos, como el de los ángeles, para responder a los ateos y los defensores de la religión natural y para el sacramento de la Penitencia. ${ }^{82}$ También es una autoridad en el tema de la relación libertad-gracia. Alegre expone la solución adoptada por

78 Bernard Lamy (1640-1715), sacerdote oratoriano y profesor de teología, tuvo una producción literaria y científica muy amplia. A partir de 1687, a petición de sus superiores, se dedicó a escribir obras eclesiásticas. La más señalada fue el Apparatus biblicus, pero también preparó otras en el campo de la historiografía. Carreyre, 1924, cols. 2550-2552.

79 Honorato Tournely (1659-1729), profesor de La Sorbona, combatió con energía las tesis jansenistas. De 1725 a 1729 publicó un curso de teología que le ganó una gran reputación, las Praelectiones theologicae de gratia Christi, quas in scholis sorbonnicis habuit Honoratus Tournely. En esta obra abordó la debatida cuestión de la gracia y adoptaba una fórmula de equilibrio entre gracia eficaz y gracia eficiente que fue muy criticada. Su teología procura tratar los temas desde las nuevas perspectivas de la teología histórica. Carreyre, 1946, cols. 1242-1244.

80 Alegre, 1789-1791, libro XIII, prop. V: por ejemplo en el tema del influjo moral de la gracia.

81 Ibidem, praefatio, p. 5; libro I, prop. XVIII; libro V, prop. II, n. 3; libro VI, prop. III, nn. 12-13; libro X, prop. I.

82 Ibidem, libro I, prop. I y XXIII; libro V, prop. X; libro XVI, prop. II. 
éste, pero no la comparte porque le parece muy semejante a la de Jansenio, aunque partan de planteamientos distintos. ${ }^{83}$ Conoce sobre todo sus Praelectiones Theologicae. Al igual que Alexandre, lo propone como modelo de galicano moderado, al explicar la potestad de los obispos.

Un uso menor tienen Cayetano, Suárez, Molina y Azor, que aparecen para explicar los temas en que destacaron estos teólogos o las controversias en que estuvieron inmersos. Así ha de citar a Luis Molina y a Suárez cuando habla de la ciencia de Dios, de la distinción entre gracia suficiente y gracia eficaz, del hombre en estado natural o elevado al fin sobrenatural. Suele disentir de sus opiniones y los cita para poner de relieve el acierto de las soluciones aportadas por Aquino ${ }^{84}$ lo que manifiesta su distanciamiento de la línea suarista propia de los jesuitas. De hecho acude casi a regañadientes a Suárez para tratar la relación entre las leyes civiles y el derecho natural, porque es quien le aporta los argumentos necesarios para contestar a Grocio y Pufendorf.

Cayetano es utilizado mucho menos, aunque tiene también cierto peso como fuente en el tema del estado de justicia original o de los sacramentos. Su carácter es secundario, detrás de Belarmino o Petau, y ni siquiera aparece en la relación de fuentes que precede a cada libro, ni tampoco nombra los libros de éste que utiliza, más bien lo contradice a veces en las interpretaciones que Cayetano hace del Aquinate. Es muy probable que no fuera un autor que utilizara de primera mano. ${ }^{85}$ Por último cabría hablar de Azor y sus Institutiones morales, fuente para los temas en torno a las capacidades del hombre en el terreno sobrenatural y para las materias de moral y su relación con la ley. Cuando Alegre tiene que hablar del probabilismo se inclina más por las tesis probabilioristas, apoyándose para argumentarlas en Azor ${ }^{86}$ Es, por otra parte, algo lógico si se tiene en cuenta que el regalismo borbónico persiguió con ahínco a los autores probabilistas. El probabilismo había sido asumido corporativamente por la Compañía, mientras que la Santa Sede

83 Ibidem, libro VII, prop. V, nn. 12-13: «Ovum ovo similius non est, quam est Janseniana argumentatio Tournellianae; sed tamen ex longe diverso principio uterque argumentatur».

84 Ejemplos de esos temas en los que Alegre disiente pueden verse en Ibidem, libro V, prop. II; libro IX, prop. XIV; libro XIV, prop. III.

85 Ibidem, libro I, prop. XX, nn. 11-12; en estos números, Alegre explica de forma muy prolija los fallos de la argumentación de Cayetano sobre la providencia al interpretar a Tomás de Aquino.

86 Resulta interesante la inclusión de Juan Azor (1559-1603) porque su obra supuso un cambio en el planteamiento metodológico de la teología moral. Ibidem, libro VIII, prop. XIV: sobre la conveniencia y licitud de la interpretación de la ley. En esta proposición Alegre pasa revista a los sistemas morales. Sobre este tema, que tuvo mucha influencia en el futuro desarrollo de la moral, puede verse Pinckaers, 2000, pp. 314-321; Molina, 1994, pp. 128s. 
promovió el probabiliorismo, sobre todo desde Benedicto XIV. Alegre, como es habitual en él, se inclina por las posturas moderadas.

También refleja algunos de los problemas suscitados por el jansenismo y expone resumidamente las doctrinas de Jansenio y Quenell sobre la libertad del hombre, el valor de la penitencia o el dolor de atrición. Muestra un gran conocimiento de Jansenio, pero no cita el Augustinus. Quizá los conociera a través de los que refutaron sus errores, como Petau y Tournely. Por una parte, lo incluye en el prolegómeno dedicado a los herejes, pero en las cuestiones acerca de la gracia expone sus tesis, de las que disiente, y lo considera un teólogo «de nombre no pequeño». ${ }^{87}$

\section{Escritores protestantes}

Propiamente no podemos hablar de fuentes protestantes, porque es bastante posible que Alegre no manejara las obras de estos autores directamente. Sólo nombra algunos libros de Lutero escritos en latín, porque expone con cierto detalle su contenido al explicar la postura protestante. Estos son De captivitate Babiloniae y un opúsculo en contra de la Misa, desarrollados sobre todo en el libro XIV dedicado a explicar la Santa Misa como el sacrificio de la Nueva Ley. ${ }^{88}$

Lógicamente las posturas de Lutero y Calvino aparecen en los libros sobre la Sagrada Escritura y la Tradición, donde Alegre discute con ellos sobre la necesidad de interpretar los libros sagrados. ${ }^{89}$ También refleja la visión pesimista que los dos tenían del hombre, incapaz de hacer actos moralmente buenos, o el concepto que transmiten de ley natural. ${ }^{90}$ Junto a los nombres de Lutero, Calvino o Zwinglio aparecen también los argumentos de otros autores protestantes menos conocidos como Brenz, fiel seguidor de Lutero, o Juan Cocleo.

La presencia de los escritores reformados es igualmente evidente en los libros dedicados a los sacramentos (libros XIV a XVI). En ellos, aparte de ser expuesta de manera desarrollada la doctrina protestante sobre los sacramentos, se hace un estudio sobre su necesidad, la presencia real en la

87 Alegre, 1789-1791, prolegomenon II, pág. 241; libro VII, prop. V, n. 12: «sed hoc negat Augustinus, et cum Augutinus, Bellarminus, Tounellius, Jansenius et alii non exigui nominis Theologi».

88 Ibidem, libro XIV, prop. V.

89 Ibidem, libro III, prop. XII y XVI.

90 Ibidem, libro VI, prop. IV, n. 23; prop. IX, n. 4; libro VII, prop. IV. 
Eucaristía, la validez de la misa como sacrificio y el valor de la Penitencia o la Unción de enfermos. Se confronta con los argumentos de Belarmino, Aquino o Suárez, para terminar con los cánones de Trento sobre esos sacramentos al final de cada libro.

\section{Autores racionalistas e ilustrados}

Hay varios temas en los que Alegre expone el pensamiento ilustrado y muestra el conocimiento que tiene de sus obras, directamente o a través de otros. Ya es admirable este esfuerzo por conocerlos y dar respuesta a los interrogantes que planteaban. Aunque hay voluntad de aprovechar lo que se pueda, en general, se distancia de la mayor parte de sus tesis.

Cuando en los prolegómenos Alegre elaboró la relación de herejes y herejías a través de los siglos, al detenerse en el siglo XVIII, los dividió en tres grupos: los deístas, los materialistas y los francmasones. Su deseo de modernidad le llevó a querer buscar en su pensamiento ideas compatibles con la fe cristiana, pero la mayor parte de las veces no tuvo más remedio que discutir con ellos e incluso descalificarlos. También, en cierta manera, los subestima. De hecho una frase que aparece con relativa frecuencia es la de considerarlos más tontos que malvados. ${ }^{91}$

Los temas en los que aparecen las ideas racionalistas e ilustradas son los relativos a la existencia de Dios, la espiritualidad e inmortalidad del alma, la religión natural, la libertad del hombre, la ley natural, el hombre social por naturaleza o la superioridad de la religión cristiana. En casi todos estos problemas aparecen los razonamientos de determinados autores como Bayle, Spinoza, Voltaire, Hobbes y Rousseau. Parece conocer en profundidad el pensamiento de estos filósofos, aunque sólo cita las obras de Bayle (Dictionnaire historique et critique), de Spinoza (Tractatus theologicopoliticus) y dice haber utilizado un tratado de Rousseau sobre la desigualdad de los hombres. ${ }^{92}$

91 Ibidem, prolegomenon II, p. 243: «Mihi quidem hi ex eorum videntur genere hominum esse, de quibus dixit Aristoteles vanos potius censendos esse, quam malos». O unas líneas más adelante los llama: «curiosa sectantes, auribus prurientes, Paganae antiquitatis admiratores, et Naturae sacerdotes, nubes sine aqua, quae omni vento doctrinae circumferuntur, venales scriptores nescientes neque quae loquuntus, neque de quibus affirmant».

92 Ibidem, libro VI, prop. II, n. 16. El tratado puede ser un discurso que Rousseau envió a la Academia de Dijon, Discours sur l'origine de l'inégalité parmi les hommes. Véase Vilanova, 1992, p. 207. 
El pensamiento de Voltaire sobre el alma humana está tan desarrollado que con toda posibilidad debió leerlo. ${ }^{93}$ Aunque afirma que estudió la doctrina de este autor sobre el alma en su tratado de metafísica, es probable que se refiriera a su Dictionnaire philosophique porque el Traité de métaphysique no llegó a ser publicado. De hecho, sigue los razonamientos que Voltaire expone en el apartado sobre el alma ${ }^{94}$ Esta obra debió aportarle, además, el conocimiento de otros autores ilustrados de los que Voltaire habla. Glosa la defensa que éste hace de Locke y de sus ideas acerca del alma. ${ }^{95}$ Bayle y Spinoza reciben un tratamiento bastante negativo, el primero es llamado con frecuencia impiorum huius temporis Philosophorum Patronus y al segundo lo considera el príncipe de los ateos..$^{96}$

Christian Wolff también es citado con amplitud, no sólo para exponer sus argumentos en contra de la inmortalidad del alma o de su materialidad, sino que aprovecha para incluirlo en una ocasión que parece dar la razón a Tomás de Aquino al hablar de la Providencia, siendo su Theologia naturalis la obra que utiliza. ${ }^{97}$ También cita y expone puntos de la obra de Malebranche De la recherche de la vérité. Junto a éstos encontramos además los nombres de Helvecio, Descartes, al que llama el Soñador, Mirabeau y Collins.

Para los temas de ley natural, de las leyes en general y sobre el origen del poder, que se tratan en algunas proposiciones del libro VI, VII y en el libro VIII, utiliza a Rousseau, Pufendorf, Grocio, Hobbes, Montesquieu y Thomasius. No está de acuerdo con ellos en la separación que establecen entre ley natural y ley divina y tampoco en su negativa a considerar inmutable la ley natural. Sin embargo, pueden observarse puntos en común en muchos otros aspectos acerca del origen del poder o de las leyes positivas. De Pufendorf conoce De iure naturae et gentium libri octo. ${ }^{98}$

Además de estos autores citados expone el pensamiento de Tindal, Huet, Locke y Saint-Evremonde sobre la religión natural o racional y con-

93 Alegre, 1789-1791, libro VI, prop. II, n. 16; Decorme, 1941, p. 225: el autor dice claramente que «es el único jesuita que sabemos de cierto haya leído a Voltaire».

94 Vilanova, 1992, p. 202; Voltaire, 1995, pp. 85-114.

95 Alegre, 1789-1791, libro VI, prop. II, n. 16.

96 Pierre Bayle ocupa un lugar destacado en la obra de Alegre, porque éste lo veía como la personificación del ateísmo. Siempre ataca muy duramente sus doctrinas, sobre todo sus tesis sobre una moral natural atea.

97 Alegre, 1789-1791, Libro I, prop. XX, n. 3: «Haec D. Thom., quem vide, ubi multis probat, divina providentia malum ab rebus non omnino excludi, cuiusque doctrinam hac in re sublimem et solidam appellat Christianus Wolfius, (Th. Nat. pág. 2, parr. 493) non ille summus Catholicae doctrinae et Scholasticae Theologiae admirator».

98 Ibidem, libro VIII, praefatio. 
tiende con ellos para demostrar que la religión cristiana no sólo es superior a las demás religiones, sino que es la única verdadera. ${ }^{99}$ Un último autor que cita, y que parece no sólo conocer sino también admirar, es Leibniz. Aunque aparece en pocas ocasiones, siempre es en sentido positivo y pone su actitud ante la filosofía como un ejemplo a imitar. ${ }^{100}$

Recibido el 11 de febrero de 2010

Aceptado el 08 de febrero de 2011

\section{Bibliografía}

Alegre, Francisco Javier: Institutionum theologicarum libri XVIII, Venetiis, Typis Antonii Zattae et filiorum, 1789-1791.

Aspe Armella, Virginia: «Criollismo y escolástica en la obra Instituciones Teológicas de Francisco Javier Alegre», Rovira Gaspar, María del Carmen y Ponce Hernández, Carolina (comp. y estudio crítico): Antología: Instituciones teológicas, Francisco Javier Alegre. Ejercitaciones arquitectónicas; Dos antiguos monumentos de arquitectura mexicana, de Pedro Márquez, México, Universidad Nacional Autónoma de México (UNAM), 2007, 11-29.

Beuchot, Mauricio: Filosofía y ciencia en el México dieciochesco, México, UNAM, 1996.

Beuchot, Filósofos mexicanos del siglo XVIII, México, UNAM, 1991.

Carreyre, Jean: «Lamy, Bernard», en Vacant, Alfred y Magenot, Eugène (dirs.):

Dictionnaire de théologie catholique contenant l'exposé des doctrines de la théologie catholique, leurs preuves et leur histoire, Paris, Letouzey et Ané, 8,1924 , cols. 2550-2552.

Carreyre, «Tournely, Honoré», Dictionnaire de théologie, 15, 1946, cols. 12421244.

Congar, Yves: «Theologie. Étude historique», Dictionnaire de théologie, 15, 1946, cols. 432-434.

Coulon, Auguste: «Gotti, Vincent-Louis», Dictionnaire de théologie, 6, 1915, cols. 1503-1507.

Decorme, Gerard: La obra de los jesuitas mexicanos durante la época colonial, 1572-1767, México, José Porrúa e Hijos, 1941.

Denzinger, Henrich: Enchiridion Symbolorum definitionum et declarationum de rebus fidei et morum, Barcinone, Herder, 1973, nn. 1501, 1597.

99 Ibidem, libro I, prop. XXII y libro X, prop. XXI.

100 Ibidem, libro VIII, praefatio, p. 5: «Recte enim de Jure philosophanti, quod monuit Leibnitius, (ep. ad Mol.), non tantum humanae tranquillitatis, sed etiam divinae amicitiae ratio habeatur, cuius possessio nobis duraturam felicitatem spondet». 
Ingold, Agustin Marie Pierre: «Baronio, Cesare», en Vacant y Magenot (dirs.): Dictionnaire de théologie, 2, 1910, col. 426.

Jedin, Hubert: Il Cardinale Baronio. L'inizio della storiografia ecclesiastica cattolica nel sedicesimo secolo, Traducción italiana de Giulio Colombi, Brescia, Morcelliana, 1982.

Mandonnet, Pierre F.: «Alexandre, Noël», en Vacant y Magenot (dirs.): Dictionnaire de théologie, 1, 1909, cols. 769-772.

Maneiro, Juan Luis y Fabri, Manuel: Vidas de mexicanos ilustres del siglo XVIII, México, Servicio de Publicaciones de la UNAM, 1989.

Méndez Plancarte, Gabriel: Humanistas del siglo XVIII, México, UNAM, 1991.

Molina, Enrique: «La encíclica «Veritatis Splendor» y los intentos de renovación de la teología moral en el presente siglo», en Scripta Theologica, 26, 1, Pamplona, 1994, 123-154.

Mondin, Battista: Storia della Teologia, t. III, Bologna, Studio Domenicano, 1996, 489-490.

Navarro, Bernabé: Cultura mexicana moderna en el siglo XVIII, México, UNAM, 1983.

Pinckaers, Servais: Las fuentes de la moral cristiana. Su método, su contenido, su historia, Pamplona, EUNSA, 2000.

Rovira Gaspar, María del Carmen: «Filosofía y Humanismo», en Rovira Gaspar y Ponce Hernández (comp. y estudio crítico): Antología: Instituciones teológicas, Francisco Javier Alegre, 2007, 31-62.

Rovira Gaspar, María del Carmen y Ponce Hernández, Carolina (comp. y estudio crítico): Antología: Instituciones teológicas, Francisco Javier Alegre, 2007.

Saranyana, Josep-Ignasi: «La Historia de la Iglesia entre el positivismo y el historicismo», Anuario de Historia de la Iglesia, 5, Pamplona, 1996, 127-150.

Saranyana, «La teología académica en México», en Saranyana, J.-I. (dir.) et al.: Teología en América latina I: Desde los orígenes a la Guerra de Sucesión (1493-1715), Madrid-Frankfurt am Main, Iberoamericana-Vervuert, 1999, 284-366.

Saranyana, Josep-Ignasi y Alejos Grau, Carmen-José: «De la Escolástica barroca a la Ilustración (1665-1767)», en Saranyana (dir.) et al.: Teología en América Latina II/1: Escolástica barroca, Ilustración y preparación de la Independencia (1665-1810), Madrid-Frankfurt am Main, IberoamericanaVervuert, 2005, 185-392.

Saranyana y Alejos Grau, «La teología en la segunda mitad del siglo XVIII», en Saranyana (dir.) et al, Teología en América Latina II/1: Escolástica barroca, Ilustración y preparación de la Independencia (1665-1810), 2005. 525-569.

Vilanova, Evangelista: Historia de la teología cristiana, III, Barcelona, Herder, 1992.

Voltaire: «Alma», en Diccionario Filosófico, I, Madrid, Temas de hoy, 1995, 85114. 